\title{
The use of remifentanil for Cesarean section in a parturient with recur- rent aortic coarctation
}

Theodore R. Manullang MD, Katharine Chun MD, Talmage D. Egan MD

Purpose: To illustrate the clinical utility of a short acting opioid (remifentanil) based general anesthetic for Cesarean section in a parturient with compromised cardiac function.

Clinical Features: A 23-yr-old primigravida, complicated by a recurrent aortic coarctation with an approximate $50 \%$ narrowing of the aortic arch, presented for elective Cesarean section at 37 wk gestational age. Initially asymptomatic, her clinical condition had deteriorated as the pregnancy progressed, with worsening episodes of mild chest pain and shortness of breath. A semi-elective Cesarean section under general anesthesia was planned at 37 wk to minimize the potential for aortic complications associated with the hemodynamic stress of labour. Remifentanil was infused at 0.05 to $0.1 \mu \mathrm{g} \cdot \mathrm{kg}^{-1} \cdot \mathrm{min}^{-1}$ with good sedation and analgesia for the placement of invasive monitors. The infusion was increased to $0.2 \mu \mathrm{g} \cdot \mathrm{kg}^{-1} \cdot \mathrm{min}^{-1}$ for induction, and combined with isoflurane 0.4 to $0.6 \%$ for maintenance of anesthesia. The patient maintained stable hemodynamics throughout and her trachea was extubated without difficulty at the end of the procedure. The newborn did not require tracheal intubation, mask ventilation or naloxone and was in excellent condition upon transfer to the well baby nursery.

Conclusion: Remifentanil, when used as part of an opioid-based general anesthetic for Cesarean section, can provide maternal hemodynamic stability with minimal neonatal respiratory depression and should allow for immediate postoperative tracheal extubation of the mother.

Objectif : Illustrer l'utilité clinique d'une anesthésie générale à base d'opioïde à action brève (rémifentanil) pour la césarienne chez une parturiente qui présente une dysfonction cardiaque.

Éléments cliniques : Une primigeste de 23 ans, qui présentait une coarctation aortique avec un rétrécissement d'environ $50 \%$ de la crosse aortique, a été admise pour une césarienne planifiée à 37 sem de grossesse. D'abord asymptomatique, son état s'est détérioré graduellement pendant la grossesse et présentait des épisodes de douleurs thoraciques légères et d'essoufflement. Une césarienne sous anesthésie générale a été planifiée à 37 sem afin de réduire la possibilité de complications aortiques associées au stress hémodynamique du travail. Le rémifentanil a été administré en perfusion de $0,05 \mathrm{à} 0,1 \mu \mathrm{g} \cdot \mathrm{kg}^{-1} \cdot \mathrm{min}^{-1}$ accompagnée d'une sédation et d'une analgésie efficaces pendant l'insertion effractive de moniteurs. La perfusion a été augmentée à $0,2 \mu \mathrm{g} \cdot \mathrm{kg}^{-1} \cdot \mathrm{min}^{-1}$ pendant l'induction et combinée à l'isoflurane de 0,4 à 0,6\% pour le maintien de l'anesthésie. Les paramètres hémodynamiques sont demeurés stables pendant l'intervention et l'extubation trachéale s'est bien déroulée à la fin de la césarienne. Le nouveau-né n'a pas eu besoin d'intubation trachéale, de ventilation au masque ou de naloxone et était en excellente condition lors de son transfert à la pouponnière.

Conclusion : Le rémifentanil qui fait partie d'une anesthésie générale à base d'opioïde pour la césarienne peut assurer la stabilité hémodynamique chez la mère et n'entraîner qu'une dépression respiratoire néonatale minimale. En outre, il permet l'extubation trachéale postopératoire immédiate de la mère.

From the Department of Anesthesiology, University Health Sciences Center, 50 North Medical Dr., Salt Lake City, UT 84132 USA. Address correspondence to: Talmage D. Egan MD. Phone: 801-581-6393; Fax: 801-581-4367; E-mail: Talmage.Egan@hsc.utah.edu Accepted for publication February 2, 2000. 


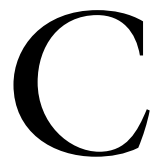

ONGENITAL heart disease is present in 7 10 of every 1000 live births, with coarctation of the aorta making up approximately $6 \%$ of these abnormalities. ${ }^{1}$ Individuals with aortic coarctation are at high risk of morbidity later in life, particularly if the lesion remains unrepaired. ${ }^{2}$ Pregnancy is associated with marked increases in maternal cardiac output and oxygen consumption. In the patient with coarctation of the aorta, these changes may lead to deterioration of a previously stable disease.

Opioid-based anesthesia is often utilized in the patient with compromised cardiac function because of its ability to obtund the response to surgical stress while minimally affecting cardiac contractility. ${ }^{3}$ In the obstetric patient, however, opioid-based anesthesia is avoided because of concerns about fetal and neonatal drug effect as well as the possible need for postoperative ventilatory support in the mother.

Remifentanil is a recently introduced, esterase metabolized synthetic opioid with an extremely short duration of action. ${ }^{4}$ Remifentanil provides intense analgesia, and has been shown to provide excellent intraoperative hemodynamic stability with rapid postoperative recovery. ${ }^{5}$

We report the case of a parturient with recurrent coarctation of the aorta who presented for a semi-elective Cesarean section in the face of deteriorating cardiac function. An opioid-based general anesthetic was performed using remifentanil. Pharmocokinetic simulations are presented and discussed.

\section{Case report}

A 23-yr-old primigravida at 37 wk estimated gestational age presented for Cesarean section. She had a history of congenital heart disease, including a patent ductus arteriosus (PDA) ligation at two months of age and an aortic coarctation and ventricular septal defect (VSD) repair at two years of age. Details of these surgical procedures were unavailable.

As part of a routine evaluation in connection with entry into an adult congenital heart program, the patient had undergone echocardiogram examination several weeks before the diagnosis of the pregnancy that had shown a small residual VSD with a left to right shunt and mitral valve prolapse. A subsequent cardiac catheterization and angiogram revealed a small apical VSD and recurrence of the aortic coarctation with a mean gradient of $20 \mathrm{~mm} \mathrm{Hg}$. The aortic valve, coronary arteries, and left ventricular function were thought to have been normal. At that time, she was asymptomatic and had essentially normal exercise tolerance. Shortly after the completion of these studies, her pregnancy was discovered.
At the outset of pregnancy, a magnetic resonance imaging (MRI) scan of the chest was performed to establish the exact location of the aortic coarctation with the plan to perform an aortic dilation if heart failure ensued later in the pregnancy. The MRI revealed a normal ascending aorta, aortic arch and great vessel origins. The coarctation was $3 \mathrm{~cm}$ distal to the origin of the left subclavian artery with an approximate 50\% narrowing as shown in Figure 1.

The second trimester of pregnancy was complicated by several episodes of mild chest pain and shortness of breath, with more severe episodes as her pregnancy advanced. She sought evaluation of her dyspnea symptoms on several occasions. Because she had no other signs or symptoms of congestive heart failure or aortic dissection, her shortness of breath symptoms were attributed to the expected reduction in functional residual capacity as a result of uterine enlargement.

At about 30 wk gestation, however, the patient began to develop claudication in her lower extremities on exertion. Over the ensuing six weeks she also began to complain of mild-moderate shortness of breath with minimal exertion. Fearing the development of congestive heart failure, amniotic fluid fetal lung maturity studies were performed at $36 \mathrm{wk}$ gestation in preparation for delivery. Because the studies suggested that the

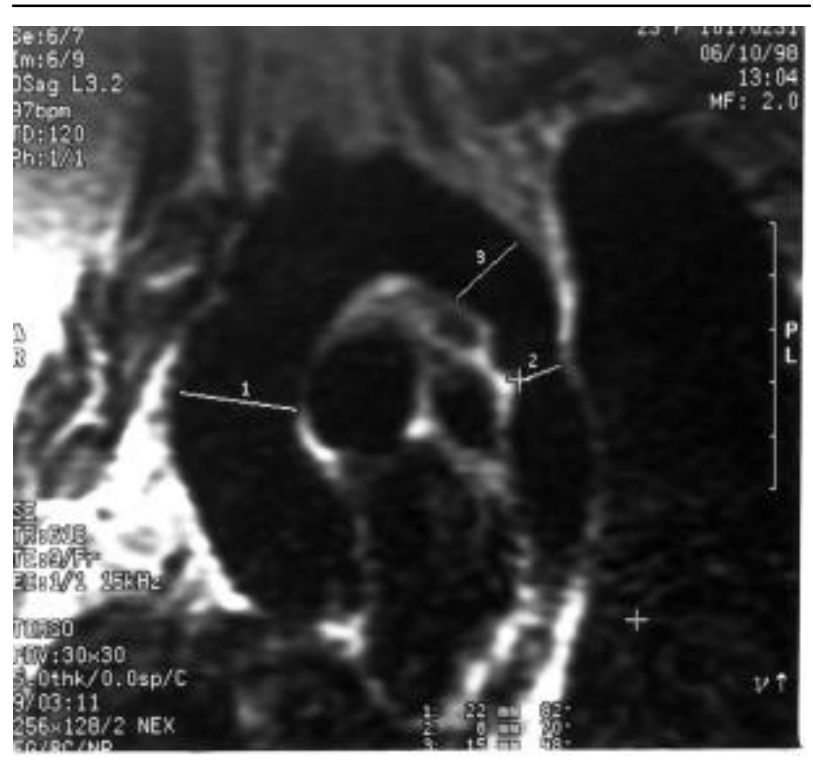

FIGURE 1 Magnetic resonance image of the chest in early pregnancy. Gated Tl weighted sagittal oblique images were obtained of the thoracic aorta. A focal coarctation of the descending thoracic aorta was present approximately $3 \mathrm{~cm}$ distal to the origin of the left subclavian artery. The coarctation had a minimum diameter of $8 \mathrm{~mm}$ (marked \#2), and extended over approximately 1.5 $\mathrm{cm}(\# 1$ = maximal diameter of ascending aorta; $\# 2$ = maximal diameter of descending aorta). 
fetal lungs were not yet sufficiently mature, a course of oral steroids was begun to promote fetal lung maturity. By 37 wk gestation, repeat examination of amniotic fluid confirmed fetal lung maturity. A semi-elective Cesarean section was planned to minimize the potential for aortic complications associated with the hemodynamic stress of labour.

The obstetric anesthesia service was consulted on the day prior to the planned Cesarean section. The patient was interviewed and examined and her medical records were reviewed. A conference was convened with the anesthesia, cardiology and obstetric services to formulate a peripartum management plan. It was agreed that, because of the potential problems associated with regional anesthesia induced preload and afterload reduction in a patient with a fixed obstruction to left ventricular ejection, general anesthesia was preferred.

After pretreatment with $30 \mathrm{ml}$ sodium citrate, the patient was brought to the operating room breathing oxygen by face mask and standard monitors were placed. On arrival, her mean arterial BP was 117 $\mathrm{mmHg}$ with a heart rate of $118 \mathrm{bpm}$. A remifentanil infusion was begun at $0.05 \mu \mathrm{g} \cdot \mathrm{kg}^{-1} \cdot \mathrm{min}^{-1}$ (based on an estimated ideal body weight of $60 \mathrm{~kg}$ ) and increased to $0.1 \mu \mathrm{g} \cdot \mathrm{kg}^{-1} \cdot \mathrm{min}^{-1}$ prior to the placement of a left radial arterial catheter and a right internal jugular central venous pressure (CVP) catheter. The patient tolerated the placement of these catheters well with minimal sedation and no evidence of muscle rigidity.

The remifentanil infusion was increased to 0.2 $\mu \mathrm{g} \cdot \mathrm{kg}^{-1} \cdot \mathrm{min}^{-1}$, and a rapid sequence induction was performed with $12 \mathrm{mg}$ etomidate $i v$ and $200 \mathrm{mg}$ succinylcholine $i v$. Isoflurane was administered at a concentration of $0.6 \%$ expired. She maintained reasonable hemodynamics prior to the delivery with mean arterial blood pressures ranging from 116 to $140 \mathrm{~mm} \mathrm{Hg}$ and heart rates ranging from 88 to $122 \mathrm{bpm}$ (maitaining the reasonably high baseline mean arterial blood pressures during the anesthetic was thought to be wise in view of the aortic coarctation). After delivery, the remifentanil infusion was increased and was maintained between 0.4 to $0.5 \mu \mathrm{g} \cdot \mathrm{kg}^{-1} \cdot \mathrm{min}^{-1}$ with isoflurane administered at a concentration of $0.4 \%$ expired. She maintained reasonable hemodynamics after delivery with mean arterial blood pressures ranging from 68 to $128 \mathrm{~mm} \mathrm{Hg}$ and heart rates from 74 to $96 \mathrm{bpm}$.

Intraoperative fluids were titrated to maintain baseline CVP of $18 \mathrm{~mm} \mathrm{Hg}$. She received a total of 1700 $\mathrm{ml}$ of lactated ringers $i v$ and had an estimated blood loss of $800 \mathrm{ml}$.

At the start of wound closure, the remifentanil infusion was decreased to $0.3 \mu \mathrm{g} \cdot \mathrm{kg}^{-1} \cdot \mathrm{min}^{-1}$ while $100 \mu \mathrm{g}$ fentanyl $i v$ were administered for postoperative analge- sia (the isoflurane vaporizer was set to zero with high fresh gas flow rates shortly before the wound closure was completed). At the conclusion of the operation, the remifentanil was discontinued and, approximately five minutes later, the patient regained consciousness (able to follow commands) and the trachea was extubated. A total of $927 \mu \mathrm{g}$ remifentanil was administered. Fentanyl was titrated in $50 \mu \mathrm{g}$ increments for pain, and she received a total of $200 \mu \mathrm{g}$ over the first $40 \mathrm{~min}$ after surgery. The patient was transferred to the ICU in stable condition and had an uneventful postoperative course. Morphine was administered by patient-controlled intravenous analgesia for the control of postoperative pain. A postoperative visit by the attending anesthesiologist confirmed the absence of awareness or other adverse effects of general anesthesia.

The delivery took place seven minutes after the induction of anesthesia with Apgar scores of 6 and 9 at one and five minutes, respectively. The newborn did not require tracheal intubation, mask ventilation or naloxone administration and was transferred to the well baby nursery. Apnea monitoring was not necessary, and the newborn had a straightforward postdelivery course.

\section{Pharmacokinetic simulations}

In order to illustrate the temporal profile of drug concentrations produced by the infusion regimen used in this report, we performed pharmacokinetic simulations based on a three-compartment mamillary model using methods described in a previous report. ${ }^{6}$ The pharmacokinetic parameters of Minto et al. were used. ${ }^{7}$ Both blood and effect- site concentrations were simulated to illustrate the time-lag between changes in blood concentration and changes in drug effect as reflected in effect-site concentrations. The parameter characterizing the disequilibrium between blood and effect-site concentrations, $\mathrm{ke}_{0}$, was also taken from our previous work. ${ }^{7}$ The simulations were implemented using an IBM personal computer running Microsoft Windows95 (Redmond, WA).

The predicted blood and effect-site concentrations, along with the corresponding infusion rates, are shown in Figure 2. These concentrations, ranging from about $\mathrm{l}$ to $12 \mathrm{ng} \cdot \mathrm{ml}^{-1}$, are consistent with studies indicating that remifentanil's therapeutic window for analgesia is from 1-5 ng. $\mathrm{ml}^{-1}$ and that, when remifentanil is used as an adjunct to general anesthesia, concentrations of from 5-15 ng. $\mathrm{ml}^{-1}$ are appropriate (opioid-based general anesthetic techniques produce concentrations that are on the higher end of this range). ${ }^{8}$

Because of the rapid equilibration of remifentanil between blood and the effect-site, the predicted effect- 


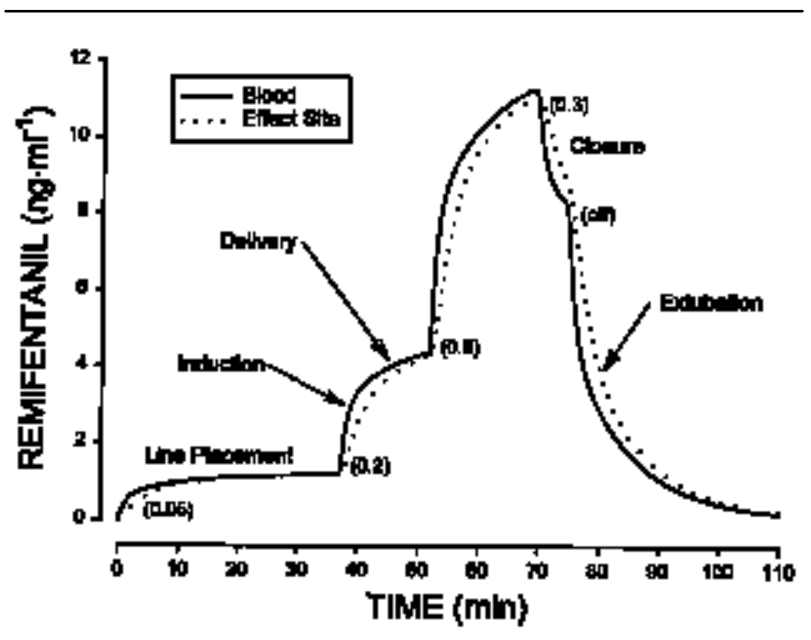

FIGURE 2 Simulated blood and effect-site concentrations of remifentanil when administered intravenously as described in this case report. The infusion rates are shown in parentheses $\left(\mu \mathrm{g} \cdot \mathrm{kg}^{-1} \cdot \mathrm{min}^{-1}\right)$.

site concentrations closely track the blood concentrations. Modifications to the remifentanil infusion rate in response to the changing needs of the operation were rapidly reflected in the remifentanil concentrations. At the time of delivery, the predicted remifentanil concentration was at a level that would be typical of its general intraoperative use; after delivery, the concentration was increased to levels that would be more representative of an "opioid-based" general anesthetic technique. At the end of the procedure, the remifentanil concentration rapidly decreased from levels that would not be expected to permit spontaneous ventilation to a level that enabled the return of spontaneous ventilation and rapid extubation of the trachea.

It should be emphasized that no data are available to clarify how the pregnant state may alter the pharmacokinetics or pharmacodynamics of remifentanil. Although our clinical experience suggests that remifentanil appears to behave in the parturient as it does in other adult patient populations, the simulations we have performed are obviously limited in this regard.

\section{Discussion}

Coarctation of the aorta in pregnancy is associated with considerable maternal and fetal morbidity. This lesion presents a fixed obstruction to the left ventricular outflow tract that causes a relative increase in blood flow to the head and upper extremities proximally and hypoperfusion to the body distally. Pregnancy exacerbates these effects, as cardiac output is greatly increased over pre-pregnancy levels. This increase in myocardial workload puts the patient at high risk for left ventricular failure. In addition, coarctation of the aorta may also be associated with decreased uterine perfusion, leading to deleterious effects on the fetus. Fetal mortality has been reported to be as high as $20 \%,{ }^{9}$ although these numbers date back several decades.

Anesthesia for the patient with compromised cardiac function has often been performed using opioid-based techniques, exploiting the technique's well recognized ability to blunt the hemodynamic response to surgical manipulation while minimally affecting cardiac contractility. ${ }^{3}$ Similar techniques have also been employed in the parturient with heart disease. For example, a relatively high dose of alfentanil has been used to provide general anesthesia for Cesarean section in patients with mitral and aortic stenosis. ${ }^{10,11}$ The main drawback of this technique in the parturient has been its respiratory depressant effects in both the parturient and the neonate. In each of these reports, for example, the newborn was apneic at the time of delivery, and required tracheal intubation and administration of parenteral naloxone. There is also concern that the mother may require a period of mechanical ventilation postoperatively.

Remifentanil, with its esterase metabolism and extremely short duration of action, does not appear to be substantially problematic in this regard. In nonpregnant subjects, remifentanil has been shown to have a context- sensitive half-time of approximately three minutes, regardless of the duration of infusion. ${ }^{12}$ This means that its concentration in the blood decreases by $50 \%$ within about three minutes of stopping the infusion. ${ }^{13}$ It shares the same rapid onset as alfentanil when given by bolus administration, while its duration of action when administered by infusion is much shorter than that of alfentanil. ${ }^{6}$ Moreover, its short duration of action is not influenced by alterations in renal or hepatic function, such as might be seen in the setting of a complicated pregnancy. ${ }^{14,15}$

The successful use of remifentanil in the obstetric population has been reported in various clinical settings. In one study involving healthy parturients undergoing Cesarean section, remifentanil was safely administered as an adjunct to epidural anesthesia. ${ }^{16}$ An infusion of $0.1 \mu \mathrm{g} \cdot \mathrm{kg}^{-1} \cdot \mathrm{min}^{-1}$ was administered throughout the course of surgery, with both maternal and umbilical cord blood samples obtained for remifentanil concentration assay at delivery. The uterine vein to maternal artery concentration ratio of 0.88 suggested rapid and extensive placental drug transfer. In addition, the uterine artery to uterine vein concentration ratio of 0.29 suggested rapid fetal metabolism and redistribution. No deleterious effects were noted in the neonates. 
Another report of an obstetrical application of remifentanil was its use to facilitate the placement of an epidural catheter in a parturient who had extreme difficulty remaining motionless during the procedure. ${ }^{17}$ In this report, remifentanil was titrated between 0.1 to $0.25 \mu \mathrm{g} \cdot \mathrm{kg}^{-1} \cdot \mathrm{min}^{-1}$, producing excellent analgesia with minimal maternal sedation. The authors believed that the remifentanil helped the parturient remain still for the placement of the epidural catheter. There was no change in the uterine contraction pattern or fetal heart rate. There were no apparent neonatal effects when the baby was delivered several hours later.

A third report of an obstetrical application for remifentanil involved its use as part of an opioid-based general anesthetic for Cesarean section in a patient with mitral valve disease. ${ }^{18}$ In that report, remifentanil was given as a bolus of $2 \mu \mathrm{g} \cdot \mathrm{kg}^{-1}$ for induction and then infused at a rate of 0.075 to $0.15 \mu \mathrm{g} \cdot \mathrm{kg}^{-1} \cdot \mathrm{min}^{-1}$ during the surgery with good hemodynamic stability and minimal neonatal respiratory depression. It should be noted that, in the present report, we saw no evidence of severe neonatal depression even though remifentanil had been administered for $47 \mathrm{~min}$ by the time the infant was delivered at a rate that was as much as three times higher than in this prior report.

Lastly, the administration of remifentanil as a patient-controlled infusion for the control of labor pain has been reported in three women with thrombocytopenia. ${ }^{9}$ The authors experimented with various dosing regimens and reported that the most effective analgesia was achieved when they utilized a patientdemand bolus of $0.5 \mu \mathrm{g} \cdot \mathrm{kg}^{-1}$ with a lockout period of two to three minutes. The patients described in this report experienced improved pain control after administration of remifentanil with no apparent long term sequelae, though one patient did experience an transient episode of maternal sedation and fetal heart rate deceleration.

Obviously, the findings of this case report must be interpreted with caution. Although remifentanil is now in widespread use as an adjunct to general anesthesia and conscious sedation and as a means of treating acute pain, experience with remifentanil in the obstetric population is limited. Although the fentanyl derivatives are not thought to affect uterine blood flow and contractility substantially, ${ }^{20}$ the effect of remifentanil on uterine physiology and uteroplacental blood flow is unknown. These and other issues may require full examination before widespread use of remifentanil can be advocated in parturients. Currently, administration of remifentanil to the parturient is not approved by the United States Food and Drug Administration.
As for the pharmacology of remifentanil in neonates, although detailed information is unavailable, it is clear that the short acting pharmacokinetic profile of remifentanil holds true for the neonate as well as for older children. ${ }^{21,22}$ However, as with the parturient, experience with remifentanil in the neonatal population is limited and remifentanil is not approved for use by the United States Food and Drug Administration in children under two years of age.

In summary, we report a case in which intravenous remifentanil may have provided advantages over previously available opioids as an adjunct in providing general anesthesia for Cesarean section in a parturient with compromised cardiac function, achieving stable hemodynamics and rapid postoperative tracheal extubation without untoward maternal and neonatal effects.

\section{References}

1 Somerville J. Congenital heart disease - changes in form and function. Br Heart J 1979; 41: 1-22.

2 Cohen M, Fuster V, Steele PM, Driscoll D, McGoon DC. Coarctation of the aorta. Long-term follow-up and prediction of outcome after surgical correction. Circulation 1989; 80: 840-5.

3 Stanley TH, Webster LR. Anesthetic requirements and cardiovascular effects of fentanyl-oxygen and fentanyldiazepam-oxygen anesthesia in man. Anesth Analg 1978; 57: 411-6.

4 Egan TD. Remifentanil pharmacokinetics and pharmacodynamics. A preliminary appraisal. Clin Pharmacokinet 1995; 29: 80-94.

5 Schuttler J, Albrecht S, Breivik H, et al. A comparison of remifentanil and alfentanil in patients undergoing major abdominal surgery. Anaesthesia 1997; 52: 307-17.

6 Egan TD, Minto CF, Hermann DJ, Barr J, Muir KT, Shafer SL. Remifentanil versus alfentanil. Comparative pharmacokinetics and pharmacodynamics in healthy adult male volunteers [published erratum appears in Anesthesiology 1996 Sep;85:695]. Anesthesiology 1996; 84: 821-33.

7 Minto CF, Schnider TW, Egan TD, et al. Influence of age and gender on the pharmacokinetics and pharmacodynamics of remifentanil. I. Model development. Anesthesiology 1997; 86: 10-23.

8 Egan TD, Muir KT, Stanski DR, Shafer SL. The EEG versus clinical measures of opioid potency: defining the EEG-clinical potency fingerprint with application to remifentanil. Anesthesiology 1996; 85: A349.

9 Deal K, Wooley CF. Coarctation of the aorta and pregnancy. Ann Intern Med 1973; 78: 706-10.

10 Batson MA, Longmire S, Csontos E. Alfentanil for urgent Caesarean section in a patient with severe mitral 
stenosis and pulmonary hypertension. Can J Anaesth 1990; 37: 685-8.

11 Redfern N, Bower S, Bullock RE, Hull CJ. Alfentanil for Caesarean section complicated by severe aortic stenosis. A case report [published erratum appears in $\mathrm{Br}$ J Anaesth 1988 Mar;60:477]. Br J Anaesth 1987; 59: 1309-12.

12 Egan TD, Lemmens HJM, Fiset P, et al. The pharmacokinetics of the new short-acting opioid remifentanil (GI87084B) in healthy adult male volunteers.

Anesthesiology 1993; 79: 881-92.

13 Kapila A, Glass PSA, Jacobs JR, et al. Measured context-sensitive half-times of remifentanil and alfentanil. Anesthesiology 1995; 83: 968-75.

14 Dershwitz $M$, Hoke JF, Rosow CE, et al. Pharmacokinetics and pharmacodynamics of remifentanil in volunteer subjects with severe liver disease. Anesthesiology 1996; 84: 812-20.

15 Hoke JF, Shlugman D, Dershwitz M, et al. Pharmacokinetics and pharmacodynamics of remifentanil in persons with renal failure compared with healthy volunteers. Anesthesiology 1997; 87: 533-41.

16 Kan RE, Hughes SC, Rosen MA, Kessin C, Preston PG, Lobo EP. Intravenous remifentanil. Placental transfer, maternal and neonatal effects. Anesthesiology 1998; 88: 1467-74.

17 Brada SA, Egan TD, Viscomi CM. The use of remifentanil infusion to facilitate epidural catheter placement in a parturient. a case report with pharmacokinetic simulations. Int J Obstet Anesth 1998; 7: 124-7.

18 Scott H, Bateman C, Price $M$. The use of remifentanil in general anaesthesia for Caesarean section in a patient with mitral valve disease. Anaesthesia 1998; 53: 695-7.

19 Jones R, Pegrum A, Stacey RGW. Patient-controlled analgesia using remifentanil in the parturient with thrombocytopaenia. Anaesthesia 1999; 54: 459-65.

20 Craft JB Jr, Coaldrake LA, Bolan JC, et al. Placental passage and uterine effects of fentanyl. Anesth Analg 1983; 62: 894-8.

21 Davis PJ, Lerman J, Suresh S, et al. A randomized multicenter study of remifentanil compared with alfentanil, isoflurane, or propofol in anesthetized pediatric patients undergoing elective strabismus surgery. Anesth Analg 1997; 84: 982-9.

22 Davis PJ, Ross AK, Henson LG, Muir KT. Remifentanil pharmacokinetics in neonates. Anesthesiology 1997; 87: A1064. 